\title{
Research of the mechanisms for coordinating the work of personnel when implementing 3D technologies
}

\author{
Olga Gritskevich*, and Valeriia Pavlenko \\ Siberian State University of Geosystems and Technologies, 630108 Novosibirsk, Russia
}

\begin{abstract}
The article is devoted to the consideration of the mechanisms for coordinating the work of personnel for the complex solution of innovative production problems at an instrument-making enterprise. The research considers the formation of coordination mechanisms in an organization, a technique is proposed that can be used to reduce the technical system lifecycle at an enterprise. The practical implementation of the coordination methodology on the example of the implementation of 3D technologies at an instrument-making enterprise contains specific proposals for the implementation of a virtual management structure, as well as a planning and personnel questionnaire system. The study is aimed to develop a methodology for the efficient use of personnel coordination mechanisms. The research object is innovative technologies at the instrument-making enterprise. The research subject is the coordination mechanisms in the context of the innovative technology deployment at the instrument-making enterprise.
\end{abstract}

\section{Introduction}

For the head of any enterprise, personnel management is a daily management task, one of the most important elements of which is the coordination of personnel work. In modern production conditions, the development of innovations is the most important process at instrument-making enterprises. Reducing the pre-production stage of the life cycle allows to significantly reduce the innovation deployment period. This can be achieved by improving staff coordination mechanisms. Therefore, the relevance of this research consists in reducing the pre-production stage of the technical system lifecycle.

\section{Study methodology}

The following research methods were used: analysis, comparison, generalization and systematization of information, apperception and the descriptive method.

The research purpose is to study the mechanisms for coordinating the work of personnel and the development of a methodology for coordinating personnel when implementing 3D technologies at an instrument-making enterprise. The methodology combines

\footnotetext{
* Corresponding author: grickevich_olga@mail.ru
} 
recommendations, whose development will allow to efficiently coordinate the work of personnel in the context of the innovative technology deployment.

Following research tasks were set to achieve the research aim:

- Investigate the theoretical issues of the formation of coordination mechanisms at the instrument-making enterprise;

- Consider the main methods of planning the activities of an instrument-making enterprise in the context of the introduction of new technical systems;

- Investigate the methodology for the coordination in the context of the introduction of new technical systems;

- Analyze the existing coordination mechanisms at the instrument-making enterprise;

- Propose a methodology for the coordination in the context of the deployment of 3D technologies at an instrument-making enterprise.

The research object is the set of innovative technologies.

The research subject is the coordination mechanisms in the context of the innovative technology deployment at the enterprise.

The scientific novelty of the research comprises the following items:

- the methodology for the efficient use of coordination mechanisms of personnel work;

- a questionnaire for interviewing staff in order to determine the efficiency of coordination;

- a virtual organizational structure based on the traditional management structure in the implementation of 3D technologies.

\section{Research results}

The methodology proposed in the work is intended for the efficient use of coordination mechanisms in the implementation of new technical systems and regulates the sequence of the following tasks $[2,3]$ :

- Selection of specialists competent in the field of innovation implementation;

- Determination of the optimum number of personnel for project implementation;

- Development of job descriptions reflecting the necessary functions, rights, and responsibilities of personnel; Appendix B contains the job description of one of the specialists involved in the implementation of new technical systems-engineer-technologist;

- Creation of a virtual organizational structure for efficient project implementation;

- Development of a network plan using software.

In addition to the methodology in the work, a questionnaire survey of personnel acts as a scientific novelty in order to determine the efficiency of coordination at the enterprise. The questionnaire was developed especially for a research. And the survey participants were 15 employees of the department of the chief optician at the instrument-making enterprise. For each positive answer there were 4 points, for a negative one - one point. Based on the answers received during the survey, it turned out that coordination in this department of the enterprise is at the proper level, since most of the employees answered positively to all the questions in the questionnaire.

The third component of scientific novelty in the work is the virtual organizational structure. The interaction of modern information technologies with the structure of the organization has led to the emergence of a new organizational structure, namely a virtual one $[1,5,11]$. A virtual structure implies the presence of permanent two or three project participants, for example, a coordination body and an IT specialist, who solve all the tasks of introducing innovations online. They involve the rest of the participants in the virtual organizational structure, for example, intermediary organizations, in order to solve a particular problem. Herewith, entire communication between the participants, as well as their 
meetings, occurs via the Internet. Now, in the era of the 21 st century, when the business environment is rapidly changing and developing, outdated traditional organizational structures of enterprises are becoming the so-called anchor, in conditions when it is necessary to quickly introduce innovation into production $[7,8,9,10]$. Therefore, the study proposes the use of a virtual organizational structure based on the traditional structure, in the context of the introduction of innovation.

The next element of the proposed methodology is the development of a network plan using software tools and implies the construction of a network schedule of works required for the implementation of 3D technologies. It is recommended to use the Microsoft Project software package as a program in which the network plan will be implemented. Microsoft Project gives the chance to define time of lagging or advancement. The project implementation schedule can be presented in the form of a Gantt chart or a network diagram. The package has ample opportunities for the reporting. It is possible to send an email to a resource at the time of assigning a task to that resource. The package contains built-in tools that provide information about the state of the project in the form of an HTML document, which greatly facilitates the work of preparing information about the state of the project for publication on the project server [4].

The main elements of a network schedule are work, event and path. Work reflects the labor process in which people, machines, mechanisms, material resources are involved. The event expresses the fact of the completion of one or several immediately preceding works necessary for the beginning of the immediately following works. Unlike jobs, events are performed instantly without consuming resources. A path is understood as any sequence of activities in the network schedule, in which the final event of each activity coincides with the initial event of the next one. The duration of the journey is determined by the sum of the durations of its constituent works. The longest path between the originating and ending events is called the critical path.

It is known that the blanks for future lenses are "turned" from optical glass. Such blanks are delivered to the enterprise in the form of large glass cubes, which are subsequently cut into several parts. Since there is a high probability that cracks and chips are formed when cutting glass, some of the material becomes unusable for further use. In order to avoid this problem, it is suggested to use a 3D printer to create lens blanks. The use of 3D printing for lens blanks implies the following algorithm of actions:

- Creation of a digital 3D model with the editor application;

- Converting a digital model into a format that a 3D printer can utilize. At this stage, a special computer slicer program divides the original 3D model into thin horizontal layers and translates it into a code that the 3D printer can understand;

- Material preparation for printing;

- 3D printing. Sending a digital 3D model prepared at the previous stage for printing. Further, the 3D printer is independently engaged in its construction. Human participation in this process is minimum.

Since lenses for optical devices undergo various manipulations, from grinding to applying scales, in this work, the use of a 3D printer is possible only in order to create blanks for future lenses. This process will be less costly, since the lens is not machined from a piece of glass with a lot of waste, but is printed only with the amount of material that is needed.

The economic efficiency of the proposed methodology can be calculated by pairwise comparison of the reduced costs and the payback period of additional capital investments. To calculate the efficiency of the implementation of 3D technologies, it is necessary to compare the costs for the two options. These are costs with and without $3 \mathrm{D}$ technology. The costs of implementing 3D printing will be efficient, since they are significantly less than those available at the enterprise. The process of introducing innovation into production will always be a capital-intensive investment, but after calculating the payback period for two options, 
we came to the conclusion that the introduction of 3D printing made it possible to shorten the payback period, and also significantly reduce the cost price, which gives the right to speak about the efficiency of the proposed innovation.

Thus, we can conclude that the use of the methodology for the efficient use of coordination mechanisms in the implementation of $3 \mathrm{D}$ technologies is more capital-intensive, but efficient, since the investments will pay off earlier than the standard period.

\section{Discussion of results}

The obtained scientific results theoretically substantiate the need for managers of instrumentmaking enterprises to take into account the peculiarities of the coordination of the work of personnel. The practical significance of the study consists in the possibility of using the developed methodology in the context of the introduction of innovations at an instrumentmaking enterprise.

The main provisions and the obtained scientific results were discussed and approved at scientific conferences. Based on the results of the study, 2 scientific articles were published within the framework of the International Scientific Conference "Economic Development of Siberia and the Far East". Interexpo Geo-Siberia-2016, 2017. As well as 1 article within the international conference "Trends and innovations in economic studies" in "The European Proceedings of Social and Behavioural Sciences" magazine in 2020. The works reveal the main theoretical provisions of personnel coordination mechanisms, describe the main provisions of the methodology proposed in the study $[2,3,4]$.

\section{Conclusions}

The paper analyzes the coordination mechanisms for various types of organization building and selects a virtual organizational structure as an additional one to the existing traditional organizational structure. The method of planning the activities of an enterprise when introducing new technical systems is considered. The practical implementation of the coordination methodology is considered on the example of the implementation of $3 \mathrm{D}$ technologies at an instrument-making enterprise and contains specific proposals for the implementation of a virtual management structure, as well as a planning and personnel questionnaire system.

The use of this technique will allow to reduce the preproduction stage of the technical system lifecycle. Such conclusions can be drawn on the basis of calculations of the efficiency of this technique. Calculations showed that the introduction of 3D technologies will be a more capital-intensive investment, but the payback period of capital investments will be lower than normalized. Herewith, the implementation costs will be minimum, taking into account the low-cost price. The above stated gives the right to talk about the efficiency of the proposed method.

\section{References}

1. N.P. Golubetskaya, I.V. Zhuk, A.V. Rozhkova, A.A. Reshetnikov, L.Ya. Zaytsev, V.I. Kolesov, D.A. Zavarin, O.Yu. Desyatnichenko, D.A. Semibratov, O.N. Grigoriev, G.H. Kim, L.V. Tserkasevich, M.A. Kosukhina, S.M. Nakenova, Z.I. Abdullaeva, A.O. Nedosekin, I.V. Nikitina, D.Yu. Desyatnichenko, collective monograph. St. Petersburg (2015)

2. O.V. Gritskevich, A.N. Chuiko, Interexpo GEO-Siberia, 60 (2016) 
3. O.V. Gritskevich, Interexpo Geo-Siberia 8, 80 (2019)

4. O.V. Gritskevich, V.A. Pavlenko, The European Proceedings of Social and Behavioural Sciences (TIES 2020). doi.org/10.15405/epsbs.2020.12.38.

5. A.N. Kozlowski, A.O. Nedosekin, Z.I. Abdoulaeva, Soft measurements and calculations 8(21), 33 (2019)

6. A. Nedosekin, A. Kozlovsky, Z. Abdoulaeva, System analysis in economics, 333 (2018)

7. V.N. Lavrov, D.K. Stozhko, A.V. Shilovtsev, Digital agriculture - development strategy. Proceedings of the International Scientific and Practical Conference, 112 (ISPC 2019)

8. D.M. Nazarov, A.S. Morozova, A.Yu. Kokovikhin, CEUR Workshop Proceedings, ICID (2019)

9. D.M. Nazarov, E.V. Dolzhenkova, Smart Innovation, Systems and Technologies 172, 691 (2020)

10. I.V. Ovchinnikova, Ye.S. Kulikova, Modern Science 11-2, 164 (2020)

11. G.N. Cherkesov, A.O. Nedosekin, V.V. Vinogradov, Reliability 18(2) (65), 17 (2018) 